\title{
A Simple and Rapid Gene Amplification from Arabidopsis Leaves Using AnyDirect System
}

\author{
Young Geun Yang ${ }^{1,2}$, Jong Yeol Kim ${ }^{2}$, Moon-Soo $\mathrm{Soh}^{3}$ and Doo-Sik Kim ${ }^{1, *}$ \\ ${ }^{1}$ Department of Biochemistry, College of Science, Yonsei University, Seoul 120-749, Korea \\ ${ }^{2}$ BioQuest, Inc., Seoul 136-865, Korea \\ ${ }^{3}$ Department of Molecular Biology, Sejong University, Seoul 143-747, Korea
}

Received 11 December 2006, Accepted 20 December 2006

\begin{abstract}
Polymerase chain reaction (PCR) is a powerful technique in molecular biology and is widely used in various fields. By amplifying DNA fragments, PCR has facilitated gene cloning procedures, as well as molecular genotyping. However, the extraction of DNA from samples often acts as a limiting step of these reactions. In particular, the extraction of PCR-compatible genomic DNA from higher plants requires complicated processes and tedious work because plant cells have rigid cell walls and contain various endogenous PCR inhibitors, including polyphenolic compounds. We recently developed a novel solution, referred to as AnyDirect, which can amplify target DNA fragments directly from whole blood without the need for DNA extraction. Here, we developed a simple lysis system that could produce an appropriate template for direct PCR with AnyDirect PCR buffer, making possible the direct amplification of DNA fragments from plant leaves. Thus, our experimental procedure provides a simple, convenient, non-hazardous, inexpensive, and rapid process for the amplification of DNA from plant tissue.
\end{abstract}

Keywords: AnyDirect, Arabidopsis, Direct PCR, Molecular marker, Simple lysis

\section{Introduction}

PCR is a powerful and useful molecular biological method that is used in biological research and diagnosis (Mattarucchi

Abbreviations: PCR: polymerase chain reaction; Col: Columbia; Ler: Lansberg erecta

*To whom correspondence should be addressed.

Tel: 82-2-2123-2700; Fax: 82-2-312-6027

E-mail: dskim@yonsei.ac.kr et al., 2005; Florencia et al., 2006). In plants, the use of PCR has many applications in plant molecular biology, including plant genotyping, gene mapping, map-based cloning, screening for transformants, marker-assisted plant breeding, and molecular ecology. In order to obtain DNA that can be used for PCR, two processes are required. The first of these processes is cell lysis using mechanical or chemical methods, such as grinding in liquid nitrogen or using detergents and/or Proteinase K. The second of these steps is the separation of DNA from various components that may interfere with PCR using organic solvents, proteinase K, salts, or membrane filters. Thus, most methods for preparing DNA from plant tissues are complicated, timeconsuming, and labor-intensive processes.

Cetyltrimethylammonium bromide (Hwang and Kim, 2000), ROSE buffer (Steiner et al., 1995), and alkaline solution (Wang et al., 1993; Xin et al., 2003) have been used to extract PCR-compatible DNA from plants more rapidly. However, most of these methods require precipitation of genomic DNA after it is separated from other cellular components with organic solvents such as phenol or/and chloroform (Kang and Yang, 2004). In plants with high polyphenolic content, polyvinylpyrrolidone is also used to remove phenolic terpenoids that bind to DNA after cell lysis (John, 1992; Kim et al., 1997).

Recently, we reported a novel solution, “AnyDirect", which is used to perform PCR directly from whole blood (Yang et $a l$., in press). This solution overcame the inhibitory effects of various chemical entities such as blood proteins or heparin, and facilitated the performance of PCR directly from whole blood without pretreatment, making use of a PCR heating step for blood cell lysis. Because plant tissue contains additional cellular components, including a cell wall, we attempted to create a condition in which simple SDS-lysate from plant tissue is subject to conventional DNA amplification by PCR using AnyDirect PCR buffer. Our procedure, which utilized AnyDirect PCR buffer, eliminated the need to perform the second process needed to obtain DNA, thereby simplifying 
the process of DNA amplification by PCR directly from plant tissue.

\section{Materials and Methods}

Growth of Arabidopsis and DNA extraction. Experiments were performed using Arabidopsis Columbia (Col-0) ecotype and Lansberg erecta (Ler) ecotype, which were obtained from the ABRC (Ohio State University, Columbus). The seedlings of Arabidopsis were grown for two weeks on Murashige-Skoog medium containing $0.8 \%$ agar under white light $\left(\mathrm{WL}, 4 \mathrm{Wm}^{-2}\right)$ at $23^{\circ} \mathrm{C}$. Genomic DNA was extracted as described by Soh (Soh, 2006).

Simple lysate from leaves of Arabidopsis. We cut leaves (1 2 mg/ leaf) from Arabidopsis using sterilized scissors, and mixed them with $100 \mu \mathrm{l}$ of diluted $5 \mathrm{X}$ Direct-N-Lyse I solution, a cocktail solution containing $1.5 \%$ SDS [100 mM Tris (pH 8.0), $25 \mathrm{mM}$ EDTA, $2 \mathrm{M} \mathrm{NaCl}, 1.5 \%$ SDS, and 3\% Tween-20] (BioQuest, Seoul, Korea). The number of cut leaves was 1, 2, 3, 4, 5, 10, or 15 , and lysis solutions were diluted at $0.25 \mathrm{X}, 0.5 \mathrm{X}, 0.75 \mathrm{X}$, or $1 \mathrm{X}$ of Direct-N-Lyse I solution. TE buffer $[10 \mathrm{mM}$ Tris and $1 \mathrm{mM}$ EDTA (pH 7.0)] was used as the control lysis solution. Leaves were placed in lysis solution, ground with a pestle, incubated at $80^{\circ} \mathrm{C}$ for $2 \mathrm{~h}$, and immediately cooled on ice. The simple lysates were centrifuged at $6,000 \mathrm{rpm}$ for $5 \mathrm{~min}$, and these supernatants were used for amplification.

Amplification of DNA fragments from a genomic DNA and a simple lysate. PCR procedures were performed with $0.2 \mathrm{mM}$ of each dNTP, $0.4 \mu \mathrm{M}$ of each primer, $2 \mathrm{U}$ of Taq DNA polymerase (BioQuest), and templates in a total volume of $50 \mu \mathrm{L}$. The PCR reaction buffers were conventional PCR buffer [10 mM Tris-HCl (pH 8.3), $50 \mathrm{mM} \mathrm{KCl}$, and $1.5 \mathrm{mM} \mathrm{MgCl}_{2}$ ] or AnyDirect PCR buffer $\left[1.5 \mathrm{mM} \mathrm{MgCl}_{2}\right]$ according to the appropriate templates, DNA, or simple lysate, respectively.

In NIT1 gene amplification, the primers used were forward primer, 5'-CCCTACATTCTACAACCATGTAGCC-3', and reverse primer, 5'-CGGAATTGATGTTTTGGACC-3', as described previously (The Arabidopsis Information Resource, TAIR). The PCR conditions included initial incubation at $94^{\circ} \mathrm{C}$ for $5 \mathrm{~min}$, followed 40 cycles [denaturation at $94^{\circ} \mathrm{C}$ for $30 \mathrm{~s}$, annealing at $52^{\circ} \mathrm{C}$ for $30 \mathrm{~s}$, and extension at $72^{\circ} \mathrm{C}$ for $\left.1 \mathrm{~min}\right]$, and a final extension step at $72^{\circ} \mathrm{C}$ for $7 \mathrm{~min}$. However, primers for the MOD1 marker were derived from the Cereon small insertion/deletion (In/Del) polymorphism database (http://www.arabidopsis.org/browse/Cereon/index.jsp); forward primer, 5'-GATTCCCACTTATCAACCATCTCC-3', and reverse primer, 5'-CGAGTATTACAAACCAAGCTTCAG-3'. PCR was conducted in the NITI PCR condition, with an annealing temperature of $57^{\circ} \mathrm{C}$. Amplicons were resolved by $2 \%$ agarose gel electrophoresis in TAE buffer and stained with ethidium bromide $(0.5 \mathrm{mg} / \mathrm{L})$.

\section{Results and Discussion}

We applied Direct-N-Lyse I solution for lysis of Arabidopsis ( $\mathrm{Col}$ and $\mathrm{Col} /$ Ler heterozygote) leaf tissue. Five leaves of two

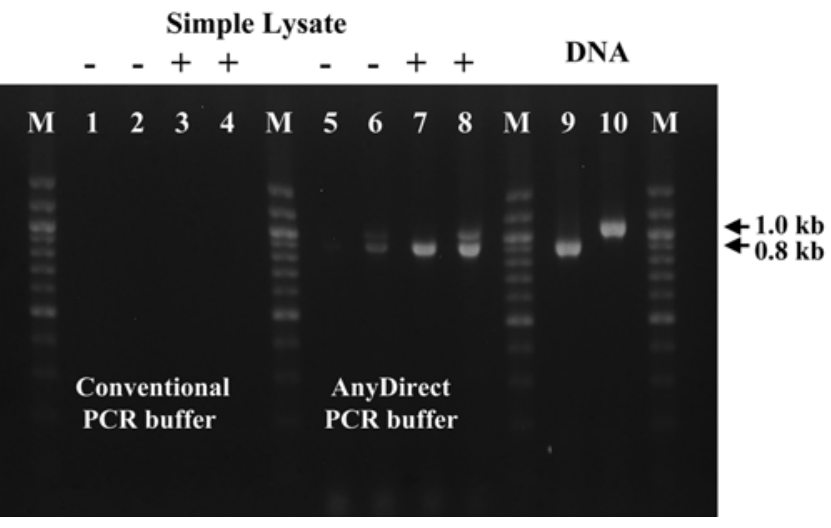

Fig. 1. Electropherogram with Arabidopsis leaf lysate and purified genomic DNA. Four leaves of Arabidopsis were mixed with $100 \mu \mathrm{L}$ of $1 \mathrm{X}$ Direct-N-Lyse I solution, ground with a pestle $(+)$ or not ground $(-)$, followed by incubation at $80^{\circ} \mathrm{C}$ for $2 \mathrm{~h}$. After heat treatment, these lysates were amplified with conventional PCR buffer (lane 1 4) and AnyDirect PCR buffer (lane 5 8). Amplification of genomic DNA from two ecotypes, Col (lane 9) and Ler (lane 10), was identified with amplicon sizes of 0.85 and $1.0 \mathrm{~kb}$, respectively. Thus, one sample (lane 1, 3, 5, and 7) was a Col homozygote, and the other (lane 2, 4, 6, and 8) was a Col/Ler heterozygote. Lane $M$ shows a $100 \mathrm{bp}$ ladder (BioQuest).

Arabidopsis ecotypes were heat-treated with $1 \mathrm{X}$ Direct-NLyse I solution. These four simple lysate solutions were then directly used as the sources of PCR templates for amplification of the NIT1 gene, of which the amplicon sizes were $0.8 \mathrm{~kb}$ and $1.0 \mathrm{~kb}$ in the Col and Ler ecotypes, respectively (Fig. 1). In a conventional PCR buffer system, amplification was not achieved, presumably due to the inhibitory effect of SDS (Fig. 1, lanes 1 4). However, the AnyDirect PCR buffer was able to amplify the NIT1 gene from both non-ground (Fig. 1, lanes 5 and 6) and ground lysates (Fig. 1, lanes 7 and 8), although the level of amplification from non-ground lysate was lower than that from the ground lysate. In contrast, the process of lysis using only SDS and heating was not sufficient for amplification of the NIT1 gene.

Next, we attempted to determine the most effective concentration of Direct-N-Lyse I solution for performing direct PCR from plant tissue. The lysates in $0.25 \mathrm{X}, 0.5 \mathrm{X}$, and $0.75 \mathrm{X}$ lysis solutions successfully served as the sources of templates for PCR with AnyDirect PCR buffer, while those with TE buffer did not (Fig. 2A, AnyDirect PCR buffer). Under our experimental conditions, one or two microliters of leaf lysate served as better templates than over three microliters of lysate for PCR with a total volume of 50 microliters. A larger volume of over three microliters of lysate might not permit successful DNA amplification, presumably due to the increment of PCR inhibitors, especially SDS. In contrast to AnyDirect PCR buffer, the use of conventional PCR buffer did not yield amplicons from leaf lysates of Direct-N-Lyse I solution, except from that of highly diluted, 
(A)
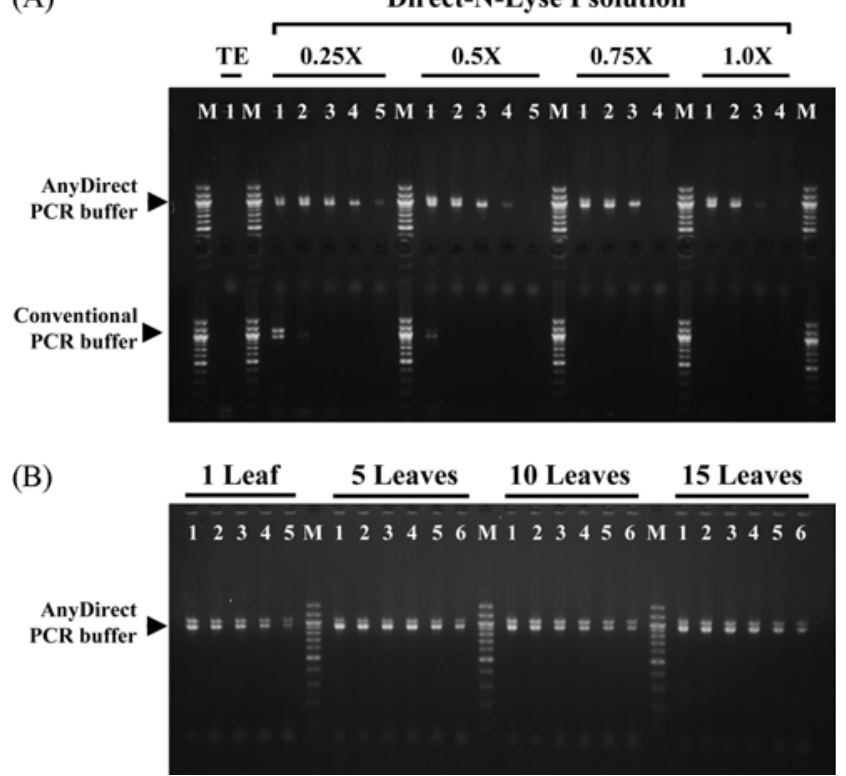

Fig. 2. Electropherogram of PCR from simple lysates with diluted Direct-N-Lyse I (A) or with the indicated amounts of leaf tissue (B). Panel A: Five leaves of Arabidopsis (Col/Ler heterozygote) in $100 \mu \mathrm{L}$ of various dilutions of Direct-N-Lyse I solution $(0.25 \mathrm{X}, 0.5 \mathrm{X}, 0.75 \mathrm{X}$, and $1 \mathrm{X})$ or $100 \mu \mathrm{L}$ TE buffer were ground with a pestle and incubated at $80^{\circ} \mathrm{C}$ for $2 \mathrm{~h}$. PCR was performed with AnyDirect PCR buffer (Upper) or with conventional PCR buffer (Lower) using various volumes of these lysates $(1,2,3,4$, and $5 \mu \mathrm{L}$; lane number indicates the volume of lysate used for PCR) in a $50 \mu \mathrm{L}$ reaction. Other PCR conditions are the same as described above. Panel B: 1, 5, 10 and 15 leaves were treated with $100 \mu \mathrm{L}$ of $1 \mathrm{X}$ Direct-N-Lyse solution and incubated at $80^{\circ} \mathrm{C}$ for $2 \mathrm{~h}$. And the lysates were diluted by two-fold serialization, $1,1 / 2,1 / 4,1 / 8,1 / 16$, and 1/32 $\mu \mathrm{L}$ (lane $1,2,3,4,5$, and 6), and were used as PCR templates in $50 \mu \mathrm{L}$ PCR reaction mixtures. PCR was performed according to the above procedure, and lane $\mathrm{M}$ shows a $100 \mathrm{bp}$ ladder.

0.25X Direct-N-Lyse I solution (Fig. 2A, Conventional PCR buffer). Because certain plant tissues are comprised of hardened cell types, the use of a strong concentration of Direct-N-Lyse I solution (e.g. 1X) may be desirable for cell lysis. Thus, we propose coupling the use of plant lysate with Direct-N-Lyse I solution with the use of AnyDirect PCR buffer for PCR.

The number of leaves used in our simple lysis method appeared not to be a critical factor in the success of PCR. The simple lysates obtained from 1, 5, 10, and 15 leaves were compared, and were shown to be sufficient for the amplification of the NIT1 gene (Fig. 2B), though the amplicon band from 1/ $16 \mu \mathrm{L}$ of one leaf was weaker than other bands (Fig. 2B, lane 5 of 1 leaf). Amplification of the MOD1 marker from simple lysate was also achieved and yielded specific amplicons from Col, Ler, and Col/Ler heterozygote, respectively (Fig. 3). Based on our results (Fig. 2, 3, and unpublished results), we propose that the appropriate amount of sample in our simple
DNA Simple Lysate

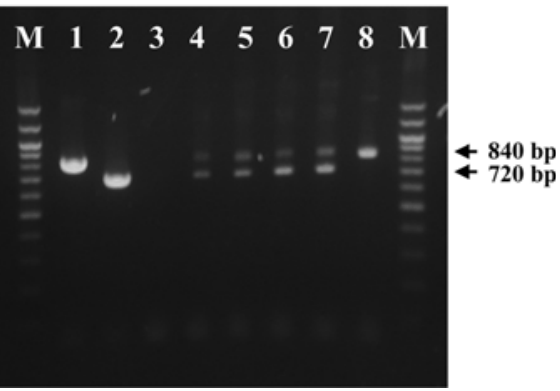

Fig. 3. The MOD1 gene amplification from Arabidopsis lysates. MOD1 (840 bp and $720 \mathrm{bp}$ from Col and Ler ecotypes, respectively) gene was amplified from Arabidopsis lysate and genomic DNA. PCR was performed with DNA from Col and Ler ecotypes (lane 1 and 2), $1 \mu \mathrm{L} \mathrm{Col} /$ Ler heterozygote lysates in TE buffer or $0.25 \mathrm{X}, 0.5 \mathrm{X}, 0.75 \mathrm{X}$, and $1 \mathrm{X}$ Direct-N-Lyse I solution (lane 3, 4, 5, 6, and 7), and $1 \mu \mathrm{L}$ Col homozygote lysate in 1X Direct-N-Lyse I solution (lane 8). No amplicon was obtained from lysate in TE buffer, as seen in Fig. 2A. Lane M shows a 100 bp ladder.

lysis system should be 5 10 Arabidopsis leaves, or 5 15 mg in $100 \mu \mathrm{L}$ solution.

We have reported that our AnyDirect PCR buffer is able to overcome the inhibitory effects of exogenous and endogenous contaminants such as SDS and hemin, and can be applied to perform direct PCR with whole blood (Yang et al., in press). Here, we examined whether our AnyDirect system is applicable for use with a plant system. Making use of detergent (SDS) treatment and crushing with a pestle in addition to heating at $80^{\circ} \mathrm{C}$, we exposed genomic nuclear DNA as a template for PCR. Though the resulting lysate would include significant amounts of PCR inhibitors as well as template DNA, our AnyDirect PCR buffer enabled the use of PCR to successfully amplify nuclear DNA fragments, thereby overriding the inhibitory effects of other components in leaf lysate. In summary, we have provided a simple lysis system that compatible with direct DNA amplification, and would make genomic DNA amplification a more rapid, simple, and safe procedure, facilitating large-scale genotyping experiments such as positional gene cloning in higher plants.

Acknowledgments This work was supported by the grant (M10640010002-06N4001-00210) from the National R\&D program of the Ministry of Science and Technology and the Korea Science and Engineering Foundation in Korea.

\section{References}

Florencia, G., Irene, S. and Veronica, F. (2006) Fragile-X Mental Retardation: Molecular Diagnosis in Argentine Patients. $J$. Biochem. Mol. Biol. 39, 766-773.

Hwang, S. K. and Kim, Y. M. (2000) A simple and reliable 
method for preparation of cross-contamination-free plant genomic DNA for PCR-based detection of transgenes. $J$. Biochem. Mol. Biol. 33, 537-546.

John, M. E. (1992) An efficient method for isolation of RNA and DNA from plants containing polyphenolics. Nucleic Acids Res. 20, 2381.

Kang, T. J. and Yang, M. S. (2004) Rapid and reliable extraction of genomic DNA from various wild-type and transgenic plants. BMC. Biotechnol. 4, 20.

Kim, C. S., Lee, C. H., Shin, J. S., Chung, Y. S. and Hyung, N. I. (1997) A simple and rapid method for isolation of high quality genomic DNA from fruit trees and conifers using PVP. Nucleic Acids Res. 25, 1085-1086.

Mattarucchi, E., Marsoni, M., Binelli, G., Passi, A., Lo, C. F., Pasquali, F. and Porta, G. (2005) Different real time PCR approaches for the fine quantification of SNP's alleles in DNA pools: assays development, characterization and pre-validation. J Biochem. Mol Biol. 38, 555-562.

Soh, M. S. (2006) Research article: Isolation and characterization of a novel mutation that confers gibberellin-sensitive dwarfism in Arabidopsis thaliana. J. Plant Biol. 25, 160-166.

Steiner, J. J., Poklemba, C. J., Fjellstrom, R. G. and Elliott, L. F. (1995) A rapid one-tube genomic DNA extraction process for PCR and RAPD analyses. Nucleic Acids Res. 23, 2569-2570.

Wang, H., Qi, M. and Cutler, A. J. (1993) A simple method of preparing plant samples for PCR. Nucleic Acids Res. 21, 41534154.

Xin, Z., Velten, J. P., Oliver, M. J. and Burke, J. J. (2003) Highthroughput DNA extraction method suitable for PCR. Biotechniques 34, 820-824, 826. 